\title{
Nuclear power for the next generation
}

\author{
The situation at Japan's Fukushima Dai-ichi nuclear power plant is dire, but should not turn the world \\ off nuclear power.
}

The scale of the disaster is overwhelming. Following the earthquake and tsunami that hit the northeast coast of Japan in March, more than 13,000 people are dead, nearly 15,000 are missing, and 150,000 are homeless. And in the wake of that devastation, further disaster threatened at the Fukushima Dai-ichi nuclear plant. The population within a $20-\mathrm{km}$ radius of the plant was evacuated and the struggle to contain and control the reactors has led to a succession of leaks of radiation levels thousands of times higher than the legal limit have been detected in the Pacific Ocean. The Tokyo Electric Power Company, which runs the plant, has now estimated that the radiation leaks can be reduced in three months, and the reactors cooled within nine months; then follows the encasing of the reactor buildings, cleaning of contaminated soil and removal of the nuclear fuel. Although the situation at Fukushima Dai-ichi is different, and has evolved differently, the incident has been rated on a par with the Chernobyl disaster of 1986.

And, like Chernobyl, it has raised fears about the safety of nuclear power and concerns about its place among the energy sources of the future. In reaction to events in Japan, nuclear-power plants around the world were closed or made subject to review: in Germany, Chancellor Angela Merkel ordered the temporary shutdown of seven of the country's oldest reactors, as anti-nuclear activists marched through the streets of Berlin (pictured) and other major cities.

Although countries such as Japan, having few natural resources for energy production, and France, through political choice, derive significant quantities of the energy they consume from nuclear power, the world as a whole is not at present reliant on nuclear sources for more than a fraction of its energy. But concerns over climate change have provoked a campaign against the continued use of fossil fuels - fossil fuels that will anyway run out one day and, as yet, renewable energy sources such as wind and solar power are not able to meet the energy needs of the planet.

Nuclear power would at least seem to be a bird in hand, a means of making up

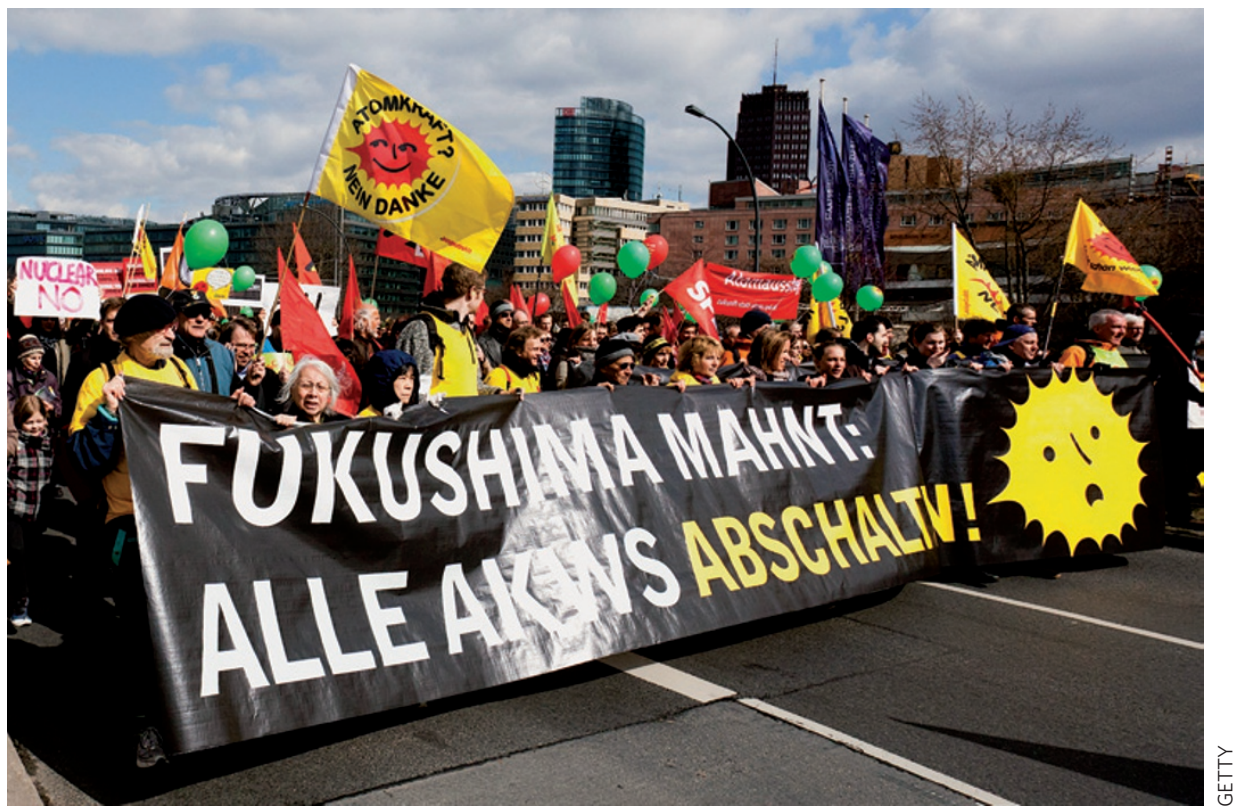

the energy budget now, and in the future. Much of the world's existing nuclear capacity is derived from the fission of uranium: radioactive waste is a problem, as is the possibility of the extraction of weapons-grade plutonium from a reactor. There is renewed interest, however, in thorium reactors, which circumvent some of the problems associated with uranium. Having been proposed as a nuclear fuel decades ago, and even used in various prototype reactors until the mid 1970s, thorium was generally overlooked in favour of uranium for, in the era of the Cold War, its weaponmaking capacity, then later again as more uranium deposits were found and its availability increased.

Yet thorium is three to four times more abundant than uranium, and is a better 'fertile' material than ${ }^{238} \mathrm{U}$ in thermal reactors (although not fast reactors) as its absorption cross-section for thermal neutrons is nearly three times higher. Its fuel cycle is intrinsically resistant to nuclear proliferation, as ${ }^{232} \mathrm{U}$ forms through $(\mathrm{n}, 2 \mathrm{n})$ reactions with ${ }^{232} \mathrm{Th},{ }^{233} \mathrm{~Pa}$ and ${ }^{233} \mathrm{U}$. For reactor designs that rely on an external accelerator to provide a neutron beam to drive the fission process, there is no 'going critical' or risk of meltdown. "No Hiroshima, no Chernobyl", says Nobel laureate and thorium advocate Carlo Rubbia.

Thorium is, however, no wonderfuel - there are still some issues over waste - but thorium cycles are feasible in existing thermal and fast reactors. India and China, in particular, are investing in future thorium technology. Meanwhile, the USA is stepping back from the forefront of the nuclear programme, choosing instead to extend the lifetime of existing reactors while shale-gas reserves are exploited. The short-term economic advantage is obvious, and the lack of vision and planning for the future worrying.

Nuclear power can be a safe part of future energy generation. The events at Fukushima Dai-ichi were extreme, the height of the tsunami peaking many times higher than any of the coastal defences that a forty-year-old reactor complex was overwhelmed is hardly surprising. Investment in reactor design and technology, coupled with proper oversight and regulation, should happen - and it should happen now. 